\title{
Studies on the Interactions between Drugs and Estrogen. III. Inhibitory Effects of 29 Drugs Reported to Induce Gynecomastia on the Glucuronidation of Estradiol
}

\author{
Takashi SAtoh, ${ }^{a}$ Yuki Tomikawa,,${ }^{b, 1)}$ Kaori Takanashi, ${ }^{b}$ Shinji IтoH,${ }^{b, *}$ Shungo ItoH, ${ }^{c}$ and \\ Itsuo YoshizaWA ${ }^{b}$ \\ ${ }^{a}$ Yakuhan Pharmaceutical Co., Ltd.; Kitahiroshima, Hokkaido 061-1111, Japan: ${ }^{b}$ Hokkaido College of Pharmacy; Otaru, \\ Hokkaido 047-0264, Japan: and ' Japan Seamen-Relief-Association Otaru Hospital; 1-7-10 Ironai, Otaru, Hokkaido \\ 047-0031, Japan. Received July 5, 2004; accepted August 27, 2004
}

To determine the inhibition effects of drugs on the glucuronidation of estradiol (E2), 29 drugs that have been reported to induce gynecomastia were examined in the presence of UDP-glucuronic acid using human hepatic microsomes (pooled) as the enzyme source. The percentage inhibition of the $\mathbf{E} 2$ glucuronidation was determined at drug concentrations of $1 \mu_{\mathrm{M}}$ (approximate therapeutic concentration) and $100 \mu_{\mathrm{M}}$ (non-clinical overdose concentration) based on the rate constants for the 3- and 17-glucuronidation of E2 (11.2 and $2.52 \mathrm{pmol} / \mathrm{min} / \mathrm{mg} \mathrm{pro}-$ tein, respectively). The only drug that exhibited $50 \%$ or higher inhibition of the 3-glucuronidation at a concentration of $1 \mu \mathrm{M}$ was manidipine $(54.4 \%)$. When the concentration was $100 \mu \mathrm{M}$, manidipine exhibited $100 \%$ inhibition of the 3-glucuronidation, and other drugs that exhibited $50 \%$ or higher inhibition of the 3-glucuronidation were nicardipine $(92 \%)$, nisoldipine $(90 \%)$, nifedipine $(84 \%)$, domperidone $(81 \%)$, tacrolimus $(80 \%)$, nitrendipine $(77 \%)$ and ketoconazole $(69 \%)$. Conversely, ipriflavone accelerated the formation of estradiol 3-glucuronide in the activity of $165 \%$ at the concentration of $100 \mu \mathrm{M}$. On the 17-glucuronidation, all of the drugs showed less than $50 \%$ inhibition at the concentration of $1 \mu \mathrm{M}$, but at the concentration of $100 \mu \mathrm{M}$, drugs that exhibited $50 \%$ or higher inhibition consisted of manidipine $(79 \%)$, chlormadinone acetate $(74 \%)$, nisoldipine $(66 \%)$, nitrendipine $(60 \%)$ and ketoconazole $(55 \%)$. Although $\mathrm{IC}_{50}$ values of these drugs were all lower than the $K_{\mathrm{m}}$ value $(285 \mu \mathrm{M})$ for the 3-glucuronidation of $\mathrm{E2}$, they were higher than the $K_{\mathrm{m}}$ value for the 17-glucuronidation $(18.8 \mu \mathrm{M})$. Thus, the effect of the drugs on the E2 glucuronidation should be greater for hydroxy group at the C-3 than that at the C-17 of E2 molecule. On the other hand, metabolic clearances $\left(V_{\max } / K_{\mathrm{m}}\right)$ of the 3- and 17-glucuronidation were about $1 / 14$ th and $1 / 18$ th of that of the 2-hydroxylation of E2, respectively. The result implies that, when the contribution of the glucuronidation to enterohepatic circulation is taken into consideration, the effect of this metabolic inhibition in the estrogen pool cannot be ignored.

Key words drug-induced gynecomastia; estradiol; UDP-glucuronosyltransferase; interaction

Although the drug-induced side effect of gynecomastia is, in many cases, considered to be a result of drug-estrogen interaction mediated by cytochrome P450 (CYP), the prediction of this side effect for inclusion in package inserts is difficult. This is because in addition to the phase I reaction, the effects of the drug on the entire enzyme system involved in the estrogen pool must be taken into consideration.

Thus far, we have attempted to construct a system for predicting drug-induced gynecomastia by not only focusing on the phase I reaction, but also extending the sites of interaction to include estrogen production and regeneration systems. By confirming drug inhibition in those systems, we intend to develop a model unit reaction system for the determination of the percentage inhibition under identical conditions, and to determine its potential for clinical application. ${ }^{2-4)}$ The results obtained are discussed below.

The main route of metabolism of estradiol (E2) in humans is the phase I reaction of 2-hydroxylation, and although there are a lot of human hepatic CYP molecules that catalyze this reaction, their individual contribution ratios are unknown. The previous studies have shown that CYP3A4 has the highest contribution ratio at roughly $71 \%,{ }^{2)}$ based on which a model unit reaction system using as reagent the recombinant CYP3A4 of an Escherichia coli expression system has been established. Next, the inhibitory effects of 29 drugs reported to induce gynecomastia on the 2-hydroxylation of E2 were investigated. Thirteen drugs of them showed high inhibition on the 2-hydroxylation, ${ }^{3)}$ but the rest 16 showed slight or no inhibition. Thus, gynecomastia by these drugs could not be explained in terms of the inhibition of the 2-hydroxylation alone.

The possible candidates for the inhibition mechanism include drug inhibition of the estrogen production system involved in the estrogen pool (aromatase pathway), the estrogen regeneration system (sulfatase pathway), and/or 17 $\beta$-hydroxysteroid dehydrogenase (17 $\beta$-HSD) and its related systems. As a result of studies on these possibilities, it was found that drugs that induce gynecomastia may also inhibit the $17 \beta$-HSD system as well as the phase I reaction of E2.,4)

The above results indicate that the phase II reaction (conjugation) must also be taken into consideration as one of the reaction systems affecting the estrogen pool (Fig. 1). The phase II reaction of E2 in humans consists primarily of the 3- or 17-glucuronidation by UDP-glucuronosyltransferase (UGT). UGT is divided into two subfamilies, UGT1 and UGT2, and each subfamily has some isoforms. ${ }^{5)}$ UGT1A1 and UGT2B7 catalyze the 3- and 17-glucuronidation of E2, respectively, yielding estradiol 3-glucuronide (E2-3G) and estradiol 17-glucuronide (E2-17G). ${ }^{6}$ Because the two UGTs have low substrate specificity and are involved in the glucuronidation of drugs and other xenobiotic substances, ${ }^{7-11)}$ the interactions between E2 and drugs are predicted.

This study was conducted for the purpose of investigating the inhibitory effects of ethical drugs on the E2 glucuronida- 


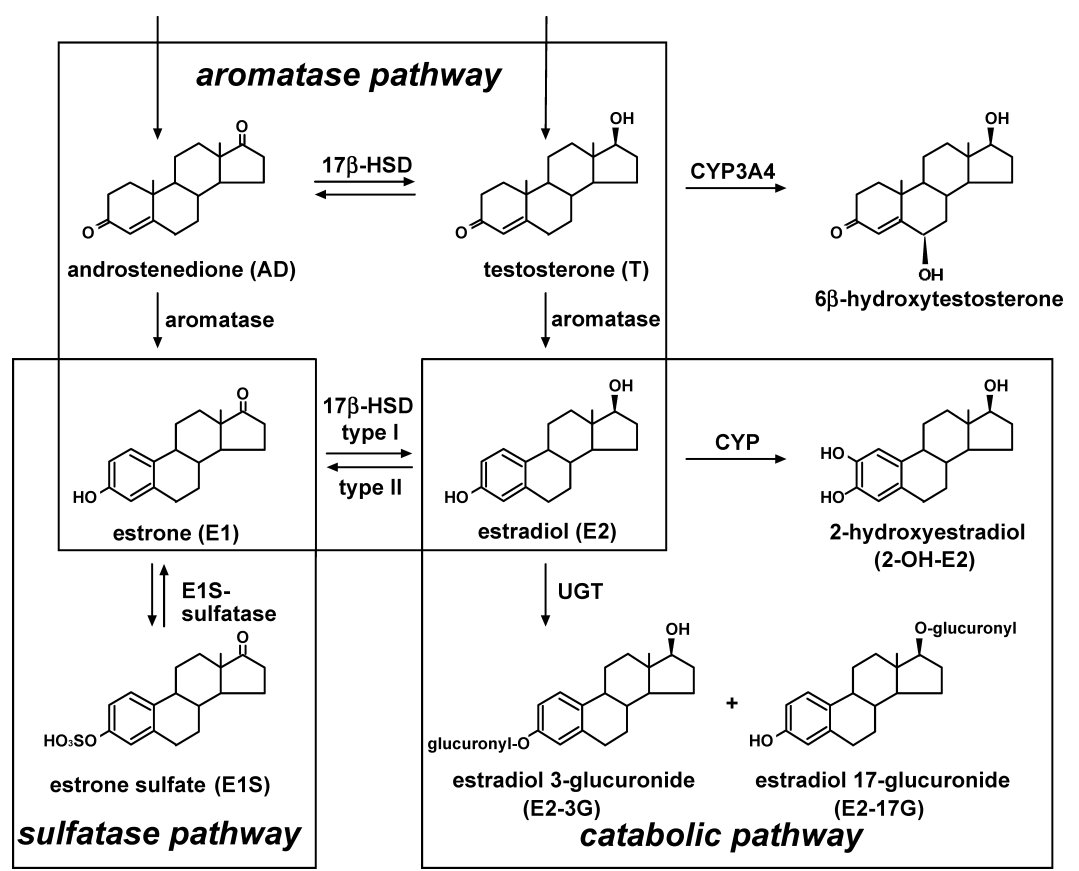

Fig. 1. Relationships of Aromatase, Sulfatase and Catabolic Pathways Related to the Estrogen Pool in Human Liver

tion, using an enzymatic reaction system having the possibility of inducing an increase of $\mathrm{E} 2$ in the estrogen pool.

\section{MATERIALS AND METHODS}

Reagents The steroidal compounds, E2, E2-3G, E2$17 \mathrm{G}$, estradiol 3,17-diglucuronide $(\mathrm{E} 2-3,17 \mathrm{G})$ and 2methoxyestradiol (2-MeO-E2) were obtained from Steraloids, Inc. (Wilton, NH, U.S.A.). As the aforementioned E2 was found to contain some impurities by HPLC, it was used after purification by recrystallization in aqueous methanol. Estradiol 17-sulfate (E2-17S) was synthesized in our laboratory according to the method of Kirdani. ${ }^{12)}$ UDP-glucuronic acid (UDPGA) was obtained from Sigma Corp. (St. Louis, MA, U.S.A.). The same lots as those of a previous study were used for the 29 drugs $^{4)}$ and for human hepatic microsomes (pooled) from ten male subjects. ${ }^{3)}$ Microsomes were used by dilution with $50 \mathrm{~mm}$ Tris- $\mathrm{HCl}$ buffer or $100 \mathrm{~mm}$ sodium-potassium phosphate buffer solution ( $\mathrm{pH}$ 7.4) as required based on the concentration indicated in the package insert. Commercially available, guaranteed reagents were used for other reagents and solvents.

HPLC HPLC analysis of E2 glucuronides was carried out under the conditions described below. A CCPE pump (Tosoh Corp., Tokyo, Japan) equipped with a Model UV8011 detector (Tosoh Corp.) was used. A stainless steel column $(250 \mathrm{~mm} \times 4.6 \mathrm{~mm}$, i.d. $)$ packed with TSK gel ODS$80 \mathrm{~T}_{\mathrm{M}}$ (Tosoh Corp.) was used for the stationary phase, and held at a temperature of $40^{\circ} \mathrm{C}$. A mixture $(50 / 50, \mathrm{v} / \mathrm{v})$ of methanol and $50 \mathrm{~mm} \mathrm{NH}_{4} \mathrm{H}_{2} \mathrm{PO}_{4}(\mathrm{pH} 3.0)$ was used as the mobile phase at a flow rate of $0.7 \mathrm{ml} / \mathrm{min}$. Analysis of the hydroxylated products of E2 in human hepatic microsomes was carried out as described in a previous report. ${ }^{2)}$

Glucuronidation of E2 The glucuronidation of E2 was conducted using the method of Czernik et al. ${ }^{13)}$ with slight modification. The incubation mixture consisted of
$100 \mathrm{~mm}$ Tris- $\mathrm{HCl}$ buffer solution $(\mathrm{pH}$ 8.5) containing $5.0 \mathrm{~mm} \mathrm{MgCl} \cdot \cdot 6 \mathrm{H}_{2} \mathrm{O}$, human hepatic microsomes (1.0 mg protein $/ \mathrm{ml}$ ) and $\mathrm{E} 2$ at six concentrations within a range from 0 to $200 \mu \mathrm{M}$. The reaction was carried out by adding $4.0 \mathrm{~mm}$ UDPGA to the incubation mixture to a final volume of $100 \mu \mathrm{l}$ and allowing to react for 0 to $60 \mathrm{~min}$ at $37^{\circ} \mathrm{C}$. The reaction was terminated by adding $100 \mu \mathrm{l}$ of methanol to the reaction mixture, followed by adding E2-17S (internal standard) and centrifuging for $10 \mathrm{~min}$ at $5000 \mathrm{rpm}$. The resulting supernatant was filtered through a membrane filter $(0.45 \mu \mathrm{m})$ and a fixed amount of the filtrate was subjected to HPLC. The inhibition experiment was conducted by preincubating $50 \mu \mathrm{M}$ E2 and drug for $5 \mathrm{~min}$, followed by addition of UDPGA and reacting for $20 \mathrm{~min}$. Fifty percent aqueous methanol was used as a solvent to dissolve the substrate and drug. The final content of methanol in the incubation mixture was $1 \%(\mathrm{v} / \mathrm{v})$. All experiments were repeated three times and the average values were used for analysis.

Assignment of the Products The glucuronide products were assigned by comparing their retention times $\left(t_{\mathrm{R}}\right)$ with those of authentic specimens (E2-3G, E2-17G and E2$3,17 \mathrm{G}$ ), and their relative retention times $\left(r t_{R}\right)$ using E2-17S as an internal standard, and also confirmed by spike experiment. For blank test, the incubation was carried out and the reaction mixture was treated by the same way as described above except the absence of the substrate.

Recovery Test A known amount ( 0 to $800 \mathrm{pmol}$ ) of authentic E2-3G or E2-17G was added to the incubation mixture, followed by addition of $100 \mu \mathrm{l}$ of methanol immediately. This mixture was then treated in the same manner as described above and submitted to HPLC.

Kinetic Parameters of E2 2-Hydroxylation The 2-hydroxylation of E2 in human hepatic microsomes was carried out according to the previous report ${ }^{2)}$ after determining the optimum reaction conditions in a preliminary experiment. The incubation mixture consisted of $100 \mathrm{~mm}$ sodium-potas- 
sium phosphate buffer solution ( $\mathrm{pH} 7.4$ ) containing $0.1 \mathrm{~mm}$ ascorbic acid, $50 \mu \mathrm{M}$ EDTA, an NADPH-generating system $\left(0.5 \mathrm{~mm} \mathrm{NDAP}^{+}, 5 \mathrm{~mm} \mathrm{MgCl}_{2}, 5 \mathrm{~mm}\right.$ glucose-6-phosphate and $1 \mathrm{U} / \mathrm{ml}$ glucose-6-phosphate dehydrogenase) and $0.25 \mathrm{mg}$ protein $/ \mathrm{ml}$ microsomes. The reaction was carried out by adding a methanolic solution of E2 (the final content of methanol: $1 \%(\mathrm{v} / \mathrm{v}))$ at nine concentrations within the range from 0 to $75 \mu \mathrm{M}$ ) to a final volume of $250 \mu \mathrm{l}$ and incubating for $10 \mathrm{~min}$ at $37^{\circ} \mathrm{C}$. To terminate the reaction was added $3 \mathrm{ml}$ of ethylacetate to the reaction mixture, followed by $2-\mathrm{MeO}-$ E2 as internal standard. After shaking for $10 \mathrm{~min}$, the mixture was centrifuged for $10 \mathrm{~min}$ at $3000 \mathrm{rpm}$. The organic layer was evaporated under reduced pressure to give the residue, which was dissolved in $100 \mu \mathrm{l}$ of $60 \%$ methanol containing $0.1 \mathrm{~mm}$ ascorbic acid, and after filtering the supernatant through a membrane filter to give the filtrate, which was injected into HPLC. The experiment was carried out in duplicate in all cases and the average values were used for analysis.

\section{RESULTS}

Analysis of E2 Conjugates A study was conducted of the conditions for separating the predicted E2 metabolites, namely, E2-3G, E2-17G and E2-3,17G, and the internal standard (E2-17S). The results are shown in Fig. 2A, where the $\mathrm{r} t_{\mathrm{R}}$ values of $\mathrm{E} 2-3,17 \mathrm{G}, \mathrm{E} 2-3 \mathrm{G}$ and $\mathrm{E} 2-17 \mathrm{G}$ were 0.3122 , 0.868 and 1.210 , respectively $(\mathrm{E} 2-17 \mathrm{~S}$ : $20.50 \mathrm{~min}=1.000)$. Although not shown in Fig. $2, t_{\mathrm{R}}$ of the peak assigned to substrate E2 was approximately $79 \mathrm{~min}$, thus indicating that all the steroids concerned were separated satisfactorily. The detection limit of each metabolite $(\mathrm{S} / \mathrm{N}=3)$ was $25 \mathrm{pmol}$ and the quantification limit $(\mathrm{S} / \mathrm{N}=10)$ was 100 pmol for $\mathrm{E} 2-3 \mathrm{G}$ and $\mathrm{E} 2-17 \mathrm{G}$, and $125 \mathrm{pmol}$ for E2-3,17G. The results of a recovery experiment of E2-3G and E2-17G are shown in Table 1. Both conjugates were recovered quantitatively.

Identification of E2 Conjugates Figures $2 \mathrm{~B}$ and $\mathrm{C}$ represent the HPLC chromatograms of the blank test and that of the E2 products, respectively. As shown in Fig. 2B, there appeared several peaks as something product-like which were derived from microsomes. The $r t_{\mathrm{R}}$ value of back ground peak at $t_{\mathrm{R}} 7.16 \mathrm{~min}$ was 0.3492 , which is fairly close to that $(0.3122)$ of E2-3,17G when the sample was spiked with authentic E2-3,17G. Figure 2C shows the microsomal products of E2, where the formation of E2-3G (peak 2) and E2-17G (peak 4) are obvious, but the peak corresponding to E2$3,17 \mathrm{G}$ was not observed.

Kinetic Analysis of Conjugation Reactions An experiment to obtain the kinetic parameters for the E2 glucuronidation was conducted by setting E2 concentration within the range from 10 to $200 \mu \mathrm{M}$. Both glucuronides were produced linearly at the substrate concentrations within the range from zero to $200 \mu \mathrm{M}$ and for the incubation time from zero to $20 \mathrm{~min}$. Lineweaver-Burk plots of the conjugation at the C-3 and the $\mathrm{C}-17$ are shown in Fig. 3A. The apparent $K_{\mathrm{m}}$ and $V_{\max }$ values of the 3- and 17-glucuronidation of E2 and their metabolic clearances $\left(V_{\max } / K_{\mathrm{m}}\right)$ are shown in Table 2 . The $K_{\mathrm{m}}$ and $V_{\max }$ values for conjugation at the C-3 were $285 \mu \mathrm{M}$ and $280 \mathrm{pmol} / \mathrm{min} / \mathrm{mg}$ protein, respectively, whereas those for conjugation at the C-17 were $18.8 \mu \mathrm{M}$ and $14.4 \mathrm{pmol} / \mathrm{min} / \mathrm{mg}$ protein, respectively. The affinity of E2 for UGT was approx-
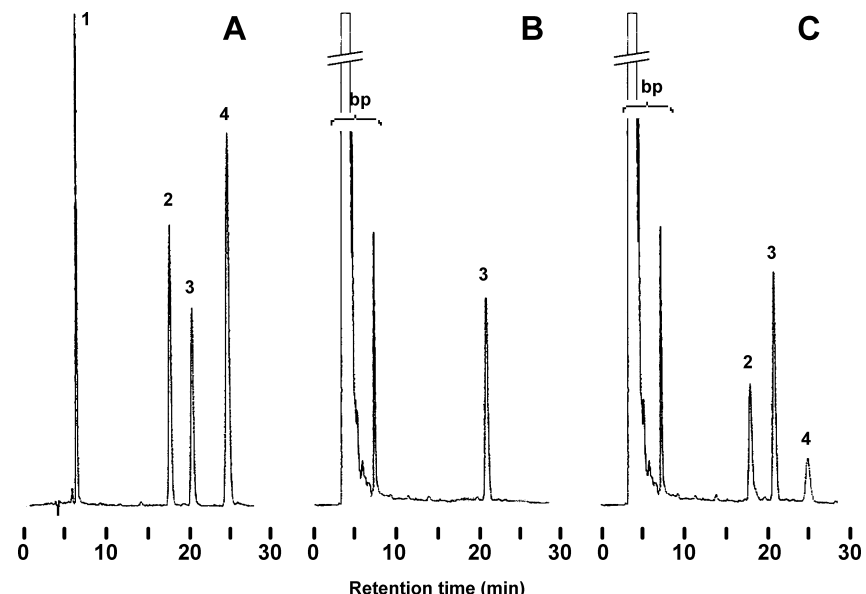

Fig. 2. HPLC Chromatograms of Authentic Steroids (A), Blank Test (B) and Incubation Products of E2 by Human Hepatic Microsomes (C)

Peaks 1, 2, 3 and 4 correspond to E2-3,17G, E2-3G, E2-17S (internal standard) and E2-17G, respectively. bp represents the product of blank test.

Table 1. Recoveries of Authentic E2-3G and E2-17G from the Incubation Medium after the Whole Clean-Up Procedure

\begin{tabular}{ccc}
\hline \hline Glucuronide & Added $(\mathrm{pmol})$ & Recovery $(\%)^{a)}$ \\
\hline \multirow{2}{*}{ E2-3G } & 100 & $97.7 \pm 4.2$ \\
& 200 & $102.3 \pm 5.5$ \\
& 400 & $98.5 \pm 1.6$ \\
E2-17G & 800 & $98.0 \pm 2.9$ \\
& 100 & $98.4 \pm 4.7$ \\
& 200 & $97.2 \pm 3.3$ \\
& 400 & $96.9 \pm 3.9$ \\
& 800 & $99.8 \pm 3.1$ \\
\hline
\end{tabular}

a) Mean \pm S.D. $(n=3)$
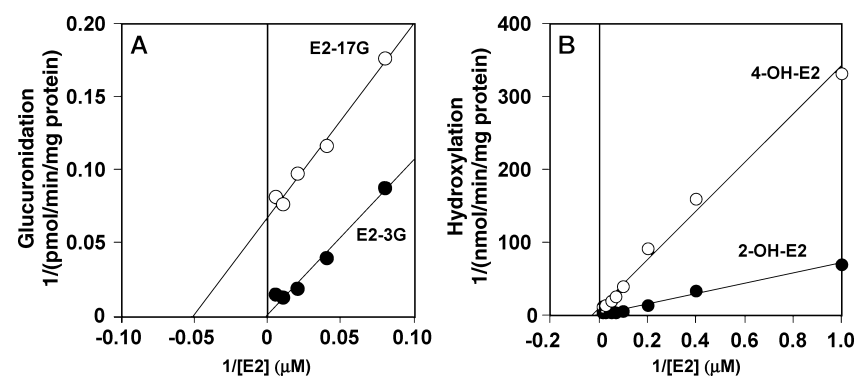

Fig. 3. Lineweaver-Burk plots for the 3- and 17-Glucuronidation of E2 (A), and the 2- and 4-Hydroxylation of E2 (B) by Human Hepatic Microsomes

Each point represents the mean value $(n=3)$.

imately 15 times higher for the 17-hydroxy group than for the 3-hydroxy group, whereas the $V_{\max }$ of the 3-glucuronidation was roughly 20 times higher than that of the 17-glucuronidation. As a result, the metabolic clearances of the 3and 17-glucuronidation were nearly the same degree, 0.98 and 0.76 , respectively.

For comparison, Lineweaver-Burk plots of the 2- and 4hydroxylation of E2 by human hepatic microsomes are shown in Fig. 3B, and their kinetic parameters are summarized in Table 2. Although the affinity for the 4-hydroxylation was two times higher than that for the 2-hydroxylation, the $V_{\max }$ was conversely nine times higher for the 2-hydroxylation than the 4-hydroxylation, and as a result, $V_{\max } / K_{\mathrm{m}}$ was 
about 5 times higher for the 2-hydroxylation than the 4-hydroxylation.

Drug Inhibition on Glucuronidation Figure 4 shows the inhibition effects of 29 drugs at the concentration of $1 \mu \mathrm{M}$ or $100 \mu \mathrm{M}$ on the formation of E2-3G (A) and E2-17G (B). The catalytic activities of the 3 - and 17-glucuronidation in the absence of drug were 11.2 and $2.52 \mathrm{pmol} / \mathrm{min} / \mathrm{mg}$ protein, respectively, and percentage inhibition shown is based on those values.

At $100 \mu \mathrm{M}$ concentration, manidipine exhibited 100\% inhibition of the E2-3G formation. This was followed by seven drugs that exhibited $50 \%$ or higher inhibition of the E2-3G formation, namely, nicardipine $(91.8 \%)$, nisoldipine $(89.6 \%)$,

Table 2. Kinetic Parameters for the Glucuronidation and Hydroxylation of E2 by Human Hepatic Microsomes

\begin{tabular}{lccc}
\hline \hline & $\begin{array}{c}K_{\mathrm{m}} \\
(\mu \mathrm{M})\end{array}$ & $\begin{array}{c}V_{\max } \\
(\mathrm{pmol} / \mathrm{min} / \\
\mathrm{mg} \text { protein })\end{array}$ & $\begin{array}{c}V_{\max } / K_{\mathrm{m}} \\
(\mu \mathrm{l} / \mathrm{min} / \\
\mathrm{mg} \text { protein })\end{array}$ \\
\hline 3-Glucuronidation & 285 & 280 & 0.98 \\
17-Glucuronidation & 18.8 & 14.4 & 0.76 \\
2-Hydroxylation & 67.1 & 940 & 14.0 \\
4-Hydroxylation & 33.2 & 100 & 3.01 \\
\hline
\end{tabular}

nifedipine $(83.8 \%)$, domperidone $(80.8 \%)$, tacrolimus (79.0\%), nitrendipine (76.5\%) and ketoconazole $(69.2 \%)$. Conversely, ipriflavone accelerated the formation instead of the inhibition, causing an increase in activity of $165 \%$. Among those drugs, only manidipine demonstrated the highest percentage inhibition of $54.4 \%$ at the concentration of $1 \mu \mathrm{M}$.

In the case of $100 \mu \mathrm{M}$ drug concentration, there were five drugs that exhibited $50 \%$ or higher inhibition of the formation of E2-17G. The strongest inhibition was demonstrated by manidipine $(79.0 \%)$, followed by chlormadinone acetate (74.1\%), nisoldipine (66.4\%), nitrendipine (60.0\%) and ketoconazole $(55.1 \%)$. All of the drugs showed less than $50 \%$ inhibition at the concentration of $1 \mu \mathrm{M}$.

The $\mathrm{IC}_{50}$ values were determined for drugs that exhibited $50 \%$ or higher inhibition of the 3- and 17-glucuronidation of E2 at a concentration of $100 \mu \mathrm{M}$. The catalytic activities of the 3- and 17-glucuronidation in the absence of drug were 11.7 and $2.41 \mathrm{pmol} / \mathrm{min} / \mathrm{mg}$ protein, respectively, which were used as control values. The results are shown in Table 3. Manidipine demonstrated the strongest inhibitory effect on E2-3G formation, exhibiting an $\mathrm{IC}_{50}$ value of $1.0 \mu \mathrm{M}$, and was followed by tacrolimus $(6.3 \mu \mathrm{M})$, nicardipine $(6.5 \mu \mathrm{M})$, nitrendipine $(8.2 \mu \mathrm{M})$, nisoldipine $(9.4 \mu \mathrm{M})$, nifedipine

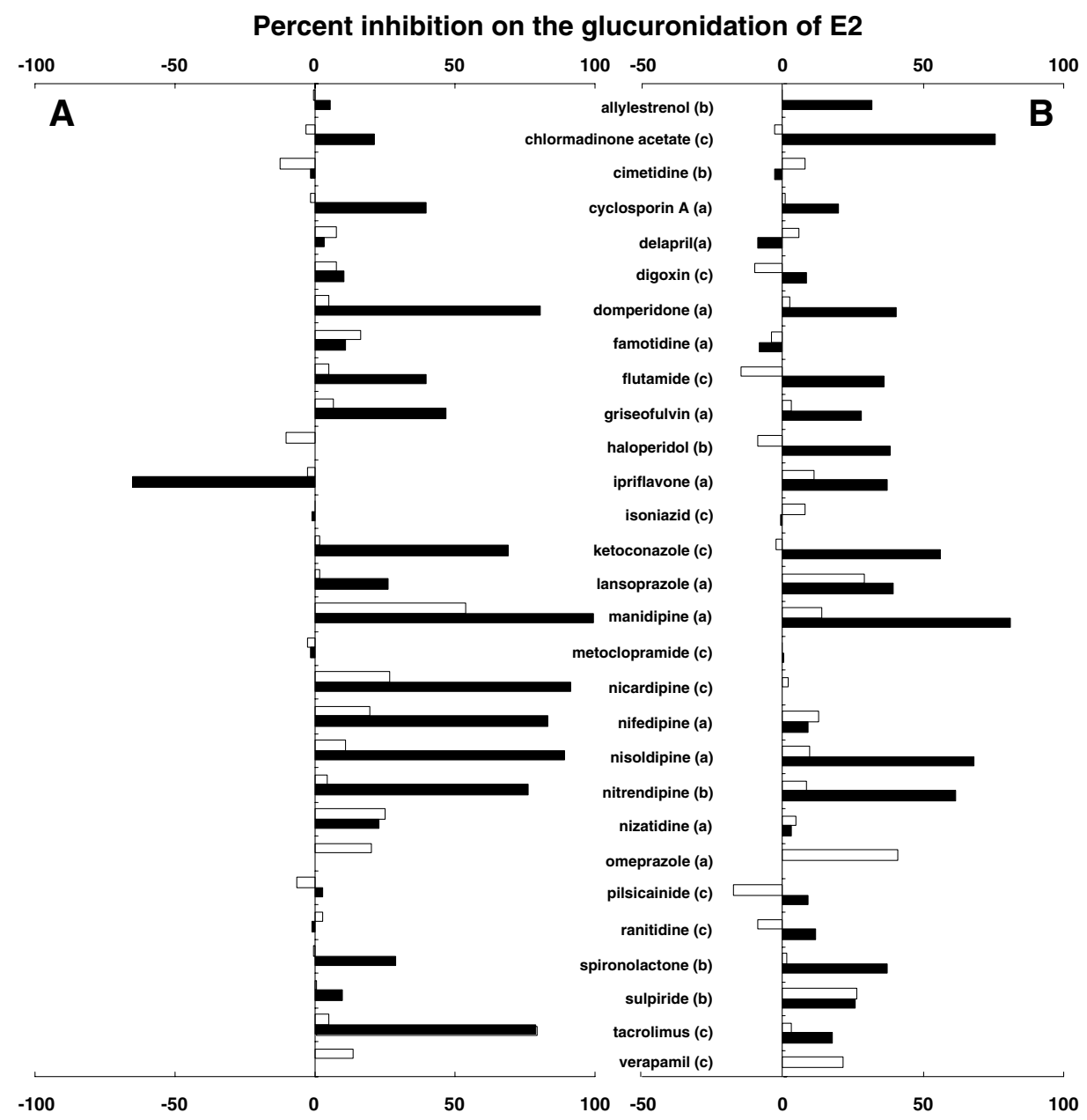

Fig. 4. Comparison of Inhibitory Effect of Drugs on the 3- and 17-Glucuronidation of E2 by Human Hepatic Microsomes

Each bar shows percent inhibition for the control, the enzyme activities of 3- (A) and 17-glucuronidation (B) were $11.2 \mathrm{and} 2.52 \mathrm{pmol} / \mathrm{min} / \mathrm{mg}$ protein, which were defined as control, respectively. Open and closed bars indicate the results obtained at drug concentration $1 \mu \mathrm{M}$ and $100 \mu \mathrm{M}$, respectively. Data are mean values obtained by triplicate determinations. The alphabet in parenthesis represents the frequency of gynecomastia associated with each drug as described in the package inserts: a, less than $0.1 \%$; b, $0.1-5 \%$; , over than $5 \%$ including "unknown". 
Table 3. Inhibitory Concentration $\left(\mathrm{IC}_{50}\right)$ of Drugs on the 3- and 17-Glucuronidation of E2 Catalyzed by Human Hepatic Microsomes

\begin{tabular}{lcc}
\hline \hline & \multicolumn{2}{c}{$\mathrm{IC}_{50}(\mu \mathrm{M})$} \\
\cline { 2 - 3 } & 3-Glucuronidation & 17-Glucuronidation \\
\hline Chlormadinone acetate & 100 & 40 \\
Domperidone & 21 & 127 \\
Ketoconazole & 39 & 83 \\
Manidipine & 1.0 & 59 \\
Nicardipine & 6.5 & $>100$ \\
Nifedipine & 16 & 9100 \\
Nisoldipine & 9.4 & 86 \\
Nitrendipine & 8.2 & 380 \\
Tacrolimus & 6.3 &
\end{tabular}

Enzymatic activities of 3- and 17-glucuronidation of E2 in the control group were 11.7 and $2.41 \mathrm{pmol} / \mathrm{min} / \mathrm{mg}$ protein, respectively. Data are shown as mean values obtained by triplicate determinations.

(16 $\mu \mathrm{M})$, domperidone $(21 \mu \mathrm{M})$ and ketoconazole $(39 \mu \mathrm{M})$. On the other hand, all of the $\mathrm{IC}_{50}$ values for $\mathrm{E} 2-17 \mathrm{G}$ formation exceeded $50 \mu \mathrm{M}$ with the exception of that of chlormadinone acetate $(40 \mu \mathrm{M})$.

\section{DISCUSSION}

The phase I reaction of estrogen in humans takes place primarily in the liver, and CYP3A4 is involved in the 2-hydroxylation of E2, which accounts for the majority of the phase I reaction. ${ }^{2)}$ In addition, a portion of E2 is subjected to the 3and 17-glucuronidation by UGT in the liver (phase II reaction). ${ }^{6,14)}$ As a similar tendency on the glucuronidation was observed in the present study using the human hepatic microsomes, the effect of drugs on the glucuronidation of E2 was investigated focusing on its two products, namely, E2-3G and E2-17G.

Because many drugs are also metabolized in the liver, the metabolic clearances were compared to determine the extent of the hydroxylation and glucuronidation of E2 catalyzed by human hepatic microsomes (Table 2). Although the clearances of the 3-and 17-glucuronidations were demonstrated as nearly same degree, and they were about $1 / 14$ th and $1 / 18$ th of that of the 2-hydroxylation of E2, respectively. However, the UGT-mediated interaction between E2 and drugs cannot be ignored for the reasons indicated below.

E2 subjected to glucuronic acid conjugation is excreted into the bile by canalicular multispecific organic anion transporter (cMOAT) $)^{6,15)} /$ multidrug resistance-associated protein 2 (MRP2) ${ }^{16)}$ on the biliary membrane in the liver, after which it is deconjugated by $\beta$-glucuronidase of intestinal bacteria. The E2, now in the form of an aglycone, is absorbed by the small intestine and migrates to the liver through the portal vein (enterohepatic circulation). ${ }^{17,18)}$ Thus, even if the metabolic clearance of E2 glucuronides is low, when the enterohepatic circulation is taken into consideration, it cannot be stated conclusively that the effects of the glucuronidation pathway on the estrogen pool are negligible. Therefore, when a drug that is subjected to glucuronidation by UGT1A1 or UGT2B7 is present, there is likely to be an increase in the number of opportunities for interaction with E2 involving these enzymes. The inhibition of E2 glucuronidation will increase the relative ratio of blood estrogen to androgen (E/A), and this may serve as a trigger that gives rise to gynecomastia.

Figure 4 shows the percentage inhibition of the 3- and 17glucuronidation of E2 by 29 drugs at an approximate therapeutic concentration of $1 \mu \mathrm{M}$ or a non-clinical overdose concentration of $100 \mu \mathrm{M}$, using the enzymatic activities obtained in the absence of drug as a control. With some exceptions, none of the drugs were found to exhibit marked inhibition at $1 \mu \mathrm{M}$. Table 3 shows the $\mathrm{IC}_{50}$ values of the drugs that exhibited $50 \%$ or higher inhibition of the E2 glucuronidation in Fig. 4. All of the $\mathrm{IC}_{50}$ values for the 3-glucuronidation were lower than the $K_{\mathrm{m}}$ value of $285 \mu \mathrm{M}$ shown in Table 2 . On the other hand, the $\mathrm{IC}_{50}$ values for the17-glucuronidation were higher than the $K_{\mathrm{m}}$ value of $18.8 \mu \mathrm{M}$, suggesting that the drugs that inhibit the 3-glucuronidation of E2 also inhibit this phase II metabolic pathway in the clinical setting as well. On the parenthesis of Fig. 4, in addition, the frequencies of gynecomastia associated with each drug as described in the package inserts ${ }^{4}$ are shown, a well-defined correlation is not observed between these drugs and the frequencies.

All of the dihydropyridine calcium antagonists investigated in this study strongly inhibited the 3-glucuronidation of E2, with manidipine showing the greatest inhibition. According to the package inserts provided by manufacturers, although these drugs are excreted as glucuronides, it is unclear which UGT species contribute to their conjugation. Our experimental results indicate the strong possibility that they are conjugated with UGT1A1.

Tacrolimus, which is used as an immunosuppressant, also strongly inhibited the 3-glucuronidation of E2 catalyzed by UGT1A1. It is interesting to note that tacrolimus, which has been reported to be catalyzed by hepatic UGT2B7, ${ }^{19)}$ demonstrates hardly any inhibitory effect on the 17-glucuronidation of E2.

Among the 29 drugs used in this study, allylestrenol, domperidone, haloperidol and metclopramide are all dopamine antagonists. As dopamine suppresses the secretion of prolactin, an anterior pituitary hormone, these drugs are thought to increase the secretion of prolactin. ${ }^{20)}$ Although the action of prolactin in men is unknown, it stimulates a development of mammary gland, causes breast enlargement and occasionally induces lactic leakage, in the same manner as in women. Thus, gynecomastia induced by these drugs is thought to occur by a mechanism different from that proposed by us based on an increase in $\mathrm{E} / \mathrm{A}$ value. In consideration of these circumstances, because the antinauseant drug, domperidone, strongly inhibited the 3-glucuronidation of E2, gynecomastia is presumed to be induced by a mechanism mediated by prolactin as well as a mechanism based on an increase in $\mathrm{E} / \mathrm{A}$ value.

Ketoconazole, an antifungal agent, is a potent inhibitor of CYP enzymes, particularly CYP3A4. We have previously reported that ketoconazole inhibits the 2-hydroxylation of E2 and that its inhibition constant ( $K_{\mathrm{i}}$ value) is $0.01 \mu \mathrm{M}{ }^{3)}$ It was clearly demonstrated in the present study that ketoconazole also strongly inhibits the 3-glucuronidation of E2. Its $\mathrm{IC}_{50}$ value $(39 \mu \mathrm{M})$ closely agreed with the $K_{\mathrm{i}}$ value of $0.08 \mathrm{~mm}^{21)}$ for the glucuronidation of the antiviral drug, zidovudine, catalyzed by human hepatic microsomes. Grosso et al. reported that ketoconazole is substituted with estrogen bound to sex steroid binding globulin present in the circulat- 
ing blood. ${ }^{22}$ Ketoconazole-induced gynecomastia is therefore thought to involve plural mechanisms accompanying an increase of $\mathrm{E} / \mathrm{A}$ value.

Ipriflavone, a synthetic isoflavone, was found to induce the formation of E2-3G at a rate equivalent to approximately 1.7 times the control value. A similar phenomenon was also reported by Williams et al. ${ }^{23}$ ) They explained that the increase in the 3-glucuronidation of E2 when E2 and flavanone are present in human hepatic microsomes is due to an allosteric effect of the UGT1A1 enzyme, or a change in the conformation of the UGT1A1 active site resulting from the binding of two substrates to the active site. The activation of E2 glucuronidation by ipriflavone, which is used for the treatment of osteoporosis, is interesting from the viewpoint of the bone metabolic regulatory action of E2. ${ }^{24)}$

Chlormadinone acetate, a steroidal anti-androgen, not only decreases serum testosterone level but also exhibits the action of lowering prolactin level. ${ }^{25)}$ As it was clearly demonstrated in this study that chlormadinone acetate inhibits, albeit weakly, the 17-glucuronidation of E2 (Table 3), this drug is considered to induce gynecomastia by increasing prolactin level and $\mathrm{E} / \mathrm{A}$ value as well.

In conclusion, on the basis of the metabolic clearance and the $\mathrm{IC}_{50}$ values of the drugs, in the E2 glucuronidation catalyzed by human hepatic microsomes, dihydropyridine calcium antagonists, domperidone, ketoconazole and tacrolimus are presumed to induce a clinical effect by inhibiting the formation of E2-3G catalyzed by UGT1A1.

\section{REFERENCES AND NOTES}

1) Present address: Sapporo Chuô Hospital, Sapporo, Hokkaido 064-0809, Japan.

2) Satoh T., Fujita K., Munakata H., Itoh Shi., Nakamura K., Kamataki T., Itoh Shu., Yoshizawa I., Anal. Biochem., 286, 179-186 (2000).

3) Satoh T., Munakata H., Fujita K., Itoh Shi., Itoh Shu., Kamataki T., Yoshizawa I., Biol. Pharm. Bull., 26, 695-700 (2003).

4) Satoh T., Itoh Shi., Seki T., Itoh Shu., Nomura N., Yoshizawa I., J. Steroid Biochem. Molec. Biol., 82, 209-216 (2002).
5) Mackenzie P. I., Owens I. S., Burchell B., Bock K. W., Bairoch A., Bélanger A., Fournel-Gigleux S., Green M., Hum D. W., Iyanagi T., Lancet D., Louisot P., Magdaloe J., Chowdhury J. R., Ritter J. K., Schachter H., Tephly T. R., Tipton K. F., Nebert D. W., Pharmacogenetics, 7, 255-269 (1997).

6) Ritter J. K., Chem.-Biol. Inter., 129, 171-193 (2000).

7) King C. D., Green M. D., Rios G. R., Coffman B. L., Owens I. S., Bishop W. P., Tephly T. R., Arch. Biochem. Biophys., 332, 92-100 (1996).

8) Ebner T., Remmel R. P., Burchell B., Molec. Pharmacol., 43, 649654 (1993).

9) Jin C., Miners J. O., Lillywhite K. J., Mackenzie P. I., J. Pharmacol. Exp. Ther, 264, 475-479 (1993).

10) Coffman B. L., Rios G. R., King C. D., Tephly T. R., Drug Metab. Dispos., 25, $1-4$ (1997).

11) Coffman B. L., King C. D., Rios G. R., Tephly T. R., Drug Metab. Dispos., 26, 73-77 (1998).

12) Kirdani R. Y., Steroids, 6, 845-853 (1965).

13) Czernik P. J., Little J. M., Barone G. W., Raufman J.-P., RadminskaPandya A., Drug Metab. Dispos., 28, 1210-1216 (2000).

14) Staczyk F. Z., Miyakawa I., Goebelsmann U., Am. J. Obstet. Gynecol., 137, $443-450$ (1980).

15) Morikawa A., Goto Y., Suzuki H., Hirohashi T., Sugiyama Y., Pharm. Res., 17, 546-552 (2000).

16) Loe D. W., Almquist K. C., Cole S. P. C., Deeley R. G., J. Biol. Chem., 271, 9683-9689 (1996).

17) Adlercreutz H., Martin F., J. Steroid Biochem., 13, $231-244$ (1980).

18) Vree T. B., Timmer C. J., J. Pharm. Pharmacol., 50, 857-864 (1998).

19) Strassburg C. P., Barut A., Obermayer-Straub P., Li Q., Nguyen N., Tukey R. H., Manns M. P., J. Hepatol., 34, 865-872 (2001).

20) Hardman J. G., Limbird L. E., Molinoff P. B., Ruddom R. W. (eds.), "Goodman \& Gilman's The Pharmacological Basis of Therapeutics," 9th ed., McGraw-Hill, New York, 1995, pp. 1370-1372.

21) Sampol E., Lacarelle B., Rajaonarison J. F., Catalin J., Durand A., Br. J. Clin. Pharmacol., 40, 83-86 (1995).

22) Grosso D. S., Boyden T. W., Pamenter R. W., Johnson D. G., Stevens D. A., Galgiani J. N., Antimicrob. Agents Chemother., 23, 207-212 (1983).

23) Williams J. A., Ring B. J., Cantrell V. E., Campanale K., Jones D. R., Hall S. D., Wrighton S. A., Drug Metab. Dispos., 30, 1266-1273 (2002).

24) Jakob F., Siggelkow H., Homann D., Köhrle J., Adamski J., Schütze N., J. Steroid Biochem. Molec. Biol., 61, 167-174 (1997).

25) Akaza H., Usami M., Kotake T., Koiso K., Aso Y., Jpn. J. Clin. Oncol., 23, $178-185$ (1993). 